Institute of $\mathbf{F}_{\text {ood and }} \mathbf{A g r i c u l t u r a l}_{\mathbf{S}} \mathbf{S}_{\text {ciences }}$

\title{
Como Realizar un Plan de Gastos - Tercer Paso: ¿Cuánto Gana Usted? ${ }^{1}$
}

Nayda I Torres ${ }^{2}$

Es tiempo de determinar cuales son sus ingresos. De esta manera usted podrá saber cuánto dinero tiene disponible para gastar y ahorrar.

Los ingresos pueden venir de diferentes fuentes. En la lista que sigue, ponga una marca a las que coinciden con su caso:

\begin{tabular}{ll}
\hline & Salario \\
& Pensión \\
& Seguro Social \\
& Desempleo \\
& Programa "Welfare" o programa de \\
& ayuda a Familias con Hijos \\
& Dependientes (AFDC, siglas en \\
& Inglés) \\
& Programa de cupones de alimentos \\
& Dinero de Parientes \\
& Otros (cuidado de niños, limpieza de \\
& casas, propinas, reciclaje, etc.)
\end{tabular}

Use la tabla que corresponda a su ciclo de pagos para determinar su ingreso mensual.

\section{Ingresos Semanales y Salario}

Dia de pago 1

Dia de pago 2

Dia de pago 3

Dia de pago 4

Dia de pago 5

\begin{tabular}{l}
$\$$ \\
\hline$\$$ \\
\hline$\$$ \\
\hline$\$$ \\
\hline$\$$
\end{tabular}

Ingresos y Salario cada 2 semanas

Dia de pago 1

Dia de pago 2 $\$$

Dia de pago 3 $\$$

Total de Ingresos

1. Este documento es la Hojuela FCS7169-Span, una serie del Departamento de Ciencias de la Familia, Juventud y Comunidad, Servicio de Extensión Cooperativa de Florida, Instituto de Alimentos y Ciencias Agrícolas, Universidad de Florida. Fecha de publicación: Octubre 2002. Por favor visite el web de EDIS http://edis.ifas.ufl.edu

2. Escrito por Nayda I. Torres, Profesora, Familia y Economía del Consumidor y la versión en Inglés ha sido revisada por Josephine Turner, CFP, Profesora, Familia y Economía del Consumidor, Servicio de Extensión Cooperativa, Departamento de Ciencias de la Familia, Juventud y Comunidad, Instituto de Alimentos y Ciencias Agrícolas, University of Florida, Gainesville, 32611. Traducido por: Sergio Romero.

El Instituto de Alimentos y Ciencias Agrícolas es un patrono que ofrece igualdad de oportunidad de empleo, autorizado a proveer investigación, información educativa y otros servicios a individuos y a instituciones que ejerzan sus funciones sin tomar en consideración raza, color, sexo, edad, incapacidad o nacionalidad. Para información sobre como obtener otras publicaciones del Servicio de Extensión, comuníquese con la Oficina del Servicio de Extensión Cooperativa de su Condado. Servicio de Extensión Cooperativa de Florida / Instituto de Alimentos y Ciencias Agrícolas / Universidad de Florida, Christine Taylor Waddill, Decano 
Sume todos los ingresos mensuales obtenidos por trabajos de jornada parcial.

\begin{tabular}{ll|}
\multicolumn{2}{c}{ Ingreso por Trabajo a Tiempo Parcial } \\
Cuidar niños & $\$$ \\
\cline { 2 - 2 } Limpiar Casas & $\$$ \\
Trabajo de Jardinería & $\$$ \\
Otros & $\$$ \\
\hline \multicolumn{2}{c|}{ Ingresos Totales por } \\
Trabajo a Tiempo Parcial
\end{tabular}

Sume todos los ingresos mensuales obtenidos de otras fuentes.

\begin{tabular}{|c|c|}
\hline \multicolumn{2}{|c|}{ Otros Ingresos } \\
\hline Seguro Social & $\$$ \\
\hline Cupones de Alimentos/WIC & $\$$ \\
\hline Pensión & $\$$ \\
\hline $\begin{array}{l}\text { Programa de Ayuda a } \\
\text { Familias (AFDC) }\end{array}$ & $\$$ \\
\hline Dinero de Familiares & $\$$ \\
\hline Total de Otros Ingresos & $\$$ \\
\hline
\end{tabular}

Sume los totales de ingresos por sueldos mensuales, trabajos a tiempo parcial y otros ingresos.

\section{Total de Ingresos}

Total Ingresos mensuales $\$$

Total de Ingresos por Trabajo a

Tiempo Parcial

Total Otros Ingresos

Total $\frac{\$}{\$} \$$

La suma total es cuánto dinero usted tiene disponible durante un mes. Las fuentes de ingreso y las cantidades que usted recibe pueden cambiar de un mes a otro.

Si usted crea el hábito de guardar buenos archivos financieros, será mucho más fácil calcular sus ingresos mensuales, como acaba de hacer aquí.

Le ayudará a averiguar exactamente cuánto puede gastar y cuanto puede ahorrar para lograr sus metas a corto y largo plazo. 